\title{
ANAESTHESIA FOR PYLOROMYOTOMY: A REVIEW (THE HOSPITAL FOR SICK CHILDREN, TORONTO)
}

\author{
A. M. DAly, M.B., B.S., F.F.A.R.C.S., AND A. W. CONN, M.D., B.SC.(MEd.), F.R.C.P.(C) ${ }^{\circ}$
}

A PREVIOUS PAPER ${ }^{1}$ reviewed the anaesthetic management of 441 patients operated on for pyloric stenosis at the Hospital For Sick Children, Turonto, from 1957 to 1960 inclusive. This paper covers an additional 537 patients treated surgically from 1961 to 1965, and compares the two groups. The entire series comprises 978 cases.

The incidence of pyloric stenosis in the western world varies from 2 to 4 per 1000 live births; it is the commonest condition requiring surgery in the first six months of life. In contrast, Gharis ${ }^{2}$ has noted a greatly decreased incidence in Israel ( 0.4 per 1000 live births) and Iran (0.08 per 1000 live births).

The lesion is present at birth and one of our cases was diagnosed the day after birth. However, symptoms rarely occur prior to two weeks of age. Multifactorial genetic factors may be involved. Carter has noted an increased incidence in children following the occurrence of pyloric stenosis in the mother. ${ }^{3}$ Studies of monozygotous twins show a 30 per cent incidence in the second twin, but in our series only one pair of four sets of twins (25\%) was affected. Also, a seasonal variation has been reported, with increased incidence in the spring and fall not accounted for by any change in birth rate. ${ }^{4}$

Many theories as to the cause of this condition have been presented. Some authors suggest that there is an arrest or delay in the development of the nerve cells of the neurogenic plexus so that they resemble those of a normal baby of an earlier age, but this has not been demonstrated in all cases. ${ }^{6}$

\section{Pathology}

The lesion in the pyloris consists of an increase in the smooth muscle mass, giving rise to the "tumour." This produces a narrowed lumen, and from this mechanical problem stem all the hazards of the condition - delayed gastric emptying, dilatation of the stomach, and regurgitation and vomiting. Because of the vomiting there is a loss of water, chloride, and hydrogen ions, resulting in a hypochloraemic acidosis. Sodium and potassium are also lost, although the chloride loss is in excess of these. Ultimately, dehydration, weight loss, and malnutrition occur. ${ }^{7}$

\section{AnAESTHEsIa}

The problems this condition presents for the anaesthetist are due to:

1. The physiological features of the newborn, an unstable cardiovascular system, the labile heat control of the young child. Under general anaesthesia ventilation may also become a problem.

'Department of Anaesthesia, Hospital for Sick Children, Toronto. 
2. The presence of a high bowel obstruction with its danger of regurgitation and aspiration, even after careful emptying of the stomach.

3. Incomplete restoration of fluid and electrolyte balance. This may precipitate circulatory insufficiency in response to surgery and anaesthesia. Such an effect was shown by three of our patients in spite of clinically good rehydration and normal electrolytes.

4. The surgical requirements of reasonable relaxation and a "quiet" operative field, particularly during the splitting of the pyloric muscle (to avoid inadvertent opening of the duodenal mucosa) and during closure of the peritoneum. If these requirements are achieved, inadequate ventilation may result unless respirations are controlled.

\section{Preoperative Preparation}

The wise anaesthetist assures himself before the operation that the patient has been rehydrated and that his haemoglobin is adequate. To ensure stability of the cardiovascular system, it is best to allow 48 hours for intravenous therapy, even if blood electrolyte levels are within normal limits earlier.

The degree of dehydration can be classified as follows:

1. Mild dehydration, and moderate alkalosis with serum bicarbonate levels below $32 \mathrm{mEq} / \mathrm{L}$. This is equivalent to 5 per cent loss of body weight. Oral preparation for surgery may be sufficient.

2. Moderate dehydration, and metabolic alkalosis, with serum bicarbonate levels between 32 and $42 \mathrm{mEq} / \mathrm{L}$. This is equivalent to 5 to 10 per cent loss of body weight. These children require parenteral fluids, usually $1 / 3$ and 73 solution up to 60 to $90 \mathrm{cc} / \mathrm{lb}$ body weight/day. Once the urinary output is adequate, potassium chloride $10 \mathrm{mEq} / \mathrm{L}$ of fluid should be given, and they may receive 5 per cent glucose in water.

3. Severe dehydration, and metabolic acidosis, with serum bicarbonate levels above $42 \mathrm{mEq} / \mathrm{L}$, equivalent to a body weight loss of more than 10 per cent. These children are wasted and malnourished. Rehydration which commences with normal saline may mask potassium deficiency, so once urinary function is assured, potassium supplements need to be given. Later 13 and $z_{3}^{\prime}$ solution is used. ${ }^{8}$

Among our 537 patients, 171 were considered dehydrated: 56 mildly, 93 moderately, and 22 severely dehydrated. Blood electrolyte estimations were done more frequently as time went on, and intravenous therapy in preparation for surgery became routine. The use of potassium chloride in resuscitating these children has removed the need for $1 \%$ molar ammonium chloride. ${ }^{8}$ If extra chloride is needed, it is best to use calcium chloride. ${ }^{9}$

Atropine was given to all patients, either intramuscularly half an hour preoperatively, or intravenously immediately prior to induction. ${ }^{10-13}$

The stomach was emptied prior to induction or awake intubation. As much as $100 \mathrm{ml}$ of contents can be found in a supposedly empty stomach. Adequate equipment for dealing with vomiting before, during, and after surgery should always be at hand even for operations under local anaesthesia.

Maintenance of temperature is essential. The child was placed on a warmed blanket and under a radiant heat lamp during preliminaries. The smaller the

I.e., 3 solution of normal saline and \%s solution of 5 per cent glucose and water. 
infant the more likely it is to lose heat during surgery. A fall in temperature may result in failure to resume breathing at the end of a general anaesthetic with controlled respiration, ${ }^{11}$ or may cause apnoea to develop in the postoperative recovery room.

All neonatal anaesthetics must be monitored, such monitors including a stethoscope, a rectal thermometer, and a blood pressure apparatus.

\section{Anaesthesia}

In our series, with one exception, all patients had general anaesthesia. There were over 80 anaesthetists (staff and residents) involved in giving these anaesthetics, and a number of different methods were used. In the second series, during 1961 and 1962, 11 patients had ethyl chloride inductions and 13 were not intubated. In 1965, ethyl chloride was no longer used, and one patient was not intubated because of inflamed cords.

\section{Induction}

Open-drop induction was used in only six cases: five in 1961 and one in 1963.

Intravenous. Thiopentone can be used to induce anaesthesia, but was reserved for larger ( $4.5 \mathrm{~kg}$ or over), more robust infants, and was administered by a skilled anaesthetist. If difficulty in intubation was anticipated, awake intubation was used. Induction with thiopentone was followed by a relaxant and immediate intubation in a previously oxygenated child. This method was used in 17 of our 537 patients. Succinylcholine may be used to facilitate intubation in a conscious infant, but it is only advisable to do this if the larynx is first visualized. ${ }^{10}$

Inhalation. Nitrous oxide and oxygen with or without halothane were used. In two cases, oxygen and cyclopropane were used. With inhalational anaesthetics, anaesthesia was deepened until intubation was possible. With halothane induction, penthrane or ether was added in some cases until anaesthesia was deep enough for intubation.

\section{Maintenance}

Intubation was accomplished on the conscious patient (186 or 32 per cent of our series) or under inhalational anaesthesia ( 321 or 59.8 per cent). Only 13 patients were not intubated. Of these 13 patients, inhalational agents only were used throughout.

Maintenance of intubated patients (524). Most of the anaesthetists used assisted or controlled ventilation. Controlled ventilation was carried out with either relaxants or inhalational agents:

1. The relaxants used were intermittent succinylcholine (the next dose being given when tone began to return) or gallamine. Nitrous oxide provided the analgesia. Relaxant-nitrous-oxide-hyperventilation technique was used in 14 cases. D-tubocurarine was not used because its longer duration of action tends to outlast the operation.

2. Any of the usual inhalational agents is satisfactory - halothane, methoxyflurane, ether, or trilene. Fairly light planes of anaesthesia, combined with hyperventilation, can provide adequate relaxation and analgesia. Anaesthesia is 
lightened once the peritoneum is closed. Inhalational agents (no relaxants) were used in 421 cases.

3. A combination of a relaxant and inhalational agents reduces the requirements of each. This method was used in 72 cases. It is important that the child be monitored continuously. Cardiac arrhythmias and blood pressure changes may develop, particularly on intubation and during delivery of the tumour, due to traction on the mesentery.

\section{Recovery}

Before extubating these small infants, it is important to see that spontaneous respiration is fully re-established. This applies after both relaxant and inhalational anaesthesia. If hyperventilation has been vigorous, with resultant alkalosis, it may be some minutes before the recovery occurs. Delayed recovery may also be due to a fall in temperature.

Careful observation is required for several hours postoperatively. The patient may collapse some time after apparently total recovery from anaesthesia. Oral feeding is begun within three to four hours of surgery. Recovery in the majority of cases is uncomplicated. Recent reports recommend continuing intravenous fluids to prevent hypoglycaemia due to hepatic glycogen depletion. The first signs of hypoglycaemia are lethargy and irritability progressing to convulsions and cardiac arrest. This is easily reversed by intravenous glucose. Early recognition and treatment are important, because the condition can lead to mental retardation. ${ }^{14}$

Smith $^{12}$ reports several babies who developed pyloric stenosis during convalescence from repair of tracheo-oesophageal fistulae. We had two such cases in our series. Both had pyloric stenosis at laparotomy, but in neither case was the diagnosis made preoperatively.

\section{Surgical}

\section{Complications}

In 20 patients the duodenal mucosa was opened, but this was recognized at operation and closed. No serious morbid sequelae developed. Two patients had a wound infection in hospital. One patient had had a previous pyloromyotomy performed.

\section{Anaesthetic}

1. Six patients vomited or regurgitated during induction. Only one may have aspirated, and he received vigorous treatment. No serious sequelae developed in any of these patients.

2. Two cases of difficult intubation were noted, and onè patient was not intubated because of an inflamed larynx.

3. In seven patients there was a delayed onset of respiration after succinylcholine.

\section{Mortality}

In 1957-60, two patients died, and an additional two in 1961-65, resulting in an overall mortality of 0.40 per cent. In the second series, both deaths occurred 
in children who were severely dehydrated and malnourished. They had received resuscitation in other hospitals before being transferred. One had aspirated, had a cardiac arrest, and been resuscitated prior to surgery. He survived 24 hours postoperatively, and died of adrenal insufficiency. The second child was severely dehydrated on arrival. Even after resuscitation, he was not considered fit for general anaesthesia. After preoxygenation he was intubated and given a local block with 0.5 per cent lignocaine. Initially, the patient recovered well from surgery, but collapsed after return to the ward, and died within 24 hours.

\section{Summary}

The anaesthetic management of patients undergoing pyloromyotomy at the Hospital for Sick Children, Toronto, during the years 1961-65 has been reviewed and discussed. Management and complications in this period have been compared with the experience of the preceding four-year period, which has been previously reported. ${ }^{1}$

\section{RÉSUMÉ}

On a fait une revue et une étude de la conduite de l'anesthésie pour les malades qui ont subi une pyloro-myotomie à l'Hôpital des enfants malades à Toronto, durant les années 1961 à 1965 . On a comparé la conduite de l'anesthésie ainsi que les complications durant cette période à ce qu'on avait observé durant les quatre années précédentes: ces observations ont déjà été rapportées. ${ }^{1}$

\section{REFERENCES}

1. Cons, A. W. Anaesthesia for Pyloromyotomy in Infants. Canad. Anaesth. Soc. J. 10: 18 (1963).

2. Charib, R. The Incidence of Infantile Pyloric Stenosis. J. Pediat. 65: 622 (1964).

3. Carter, C. O. Congenital Malformations: Papers and Discussions of the Second International Conference. International Medical Congress, Ltd. (1963) p. 309.

4. Kwor, H. M. \& Avery, G. Seasonal Variations of Congenital Hypertrophic Pyloric Stenosis. J. Pediat. 70: 963 (1967).

5. Fhiesen, S. R. \& Pearce, A. G. E. Pathogenesis of Congenital Pyloric Stenosis. Surgery. 52: 604 (1963).

6. Dennison, W. Surgery in Infancy and Childhood. Edinburgh: Livingstone (1967).

7. Howe, C. T. \& Le Quesne, L. P. Pyloric Stenosis: The Metabolic Effects. Brit. J. Surg. $51:(1964)$.

8. Benson, C. D. \& Lloyd, J. R. Infantile Pyloric Stenosis: A Review of 1120 Cases. Am. J. Surg. 107: 604 (1964).

9. Cooke, R. E. The Biological Basis of Paediatric Practice. New York: McGraw Hill (1968).

10. Wilton, T. N. \& Wilson, F. Neonatal Anaesthesia. Oxford: Blackwell (1965).

11. Grey, T. C. \& Evans, F. T. General Anaesthesia, vol. 2. London: Butterworths (1965), p. 433.

12. Smith, R. M. Anaesthesia for Infants and Children. Ind ed., St. Louis: Mosby (1963), p. 248.

13. Wylie, W. D. \& Churchill-Davinson, H. C. A Practice of Anaesthesia. 2nd ed., Chicago: Year Book Publishers (1966), p. 1159.

14. Henderson, B. M.; Schubert, W. K.; Hug, G.; \& Martin, L. W. Hypoglyciemia with Hepatic Glycogen Depletion: A Postoperative Complication. J. Pediat. Surg. 3: 309 (1968). 